\title{
Incorporation of Ascorbic Acid, Caffeine and Chloroquine Diphosphate in Dilutor Improves Structural and Functional Status of Frozen Semen
}

\author{
S. Srivastava1, Satish Kumar ${ }^{2}$ \\ ${ }^{1}$ College of Veterinary Science, Faizabad, India \\ ${ }^{2}$ Division of PR\&SM, Central Institute for Research on Goats, Makhdoom, India \\ Email: skumarars@rediffmail.com
}

Received 5 November 2013; revised 13 December 2013; accepted 26 December 2013

Copyright (C) 2014 by authors and OALib.

This work is licensed under the Creative Commons Attribution International License (CC BY). http://creativecommons.org/licenses/by/4.0/ (c) (i) Open Access

\begin{abstract}
Effect of supplementation of ascorbic acid, caffeine and chloroquine diphosphate in the dilutor on post-thaw quality of spermatozoa was studied. Thirty-two semen ejaculates (8 each from 2 Holstein Friesian and 2 crossbred; 50\% Friesian x 50\% Haryana) were studied. Ascorbic acid, caffeine and chloroquine diphosphate were added in Tris-egg yolk-glycerol (control) extender at the concentration of $10 \mathrm{mM}, 0.54 \mathrm{mM}$ and $7 \mathrm{mM}$, respectively. The post-thaw semen parameters studied were structural (acrosomal integrity and livability), functional [motility, per cent sperm responding to hypo-osmotic swelling test, i.e. HOS positive sperm and penetrability of sperm in bovine cervical mucus, i.e. sperm penetration distance-SPD] and measurement of activities of Glutamic oxaloacetic transaminase (GOT), Glutamic pyruvic transaminase (GPT), Alkaline transaminase (AKP) and Acid transaminase (ACP). Certain enzymes in the seminal plasma. The semen from crossbred bull had significantly lower mass activity $(P \leq 0.01)$, initial progressive motility $(P \leq 0.01)$, sperm penetration distance (SPD value) ( $P \leq 0.01)$, HOS positive sperm and seminal plasma GOT activity, but higher abnormal sperm. Incorporation of additives in the dilutor significantly improved the post-thaw semen quality, especially the post-thaw motility, post-thaw per cent live sperm, sperm penetration distance and sperm responding to hypo-osmotic solution. The leakage of all the 4 enzymes (GOT, GPT, ACP and AKP) was significantly less in the samples frozen in presence of ascorbic acid and chloroquine as compared to control. Ascorbic acid resulted in maximum improvement to the quality of frozen-thawed semen followed by chloroquine and caffeine. The study concludes that post-thaw quality of frozen semen of HF and crossbred bulls significantly improves if the dilutor is supplemented with $10 \mathrm{mM}$ concentration of ascorbic acid.
\end{abstract}




\section{Keywords}

\section{Semen; Freezing; Ascorbic Acid; Caffeine; Chloroquine; Sperm Penetration Distance; Hypo-Osmotic Swelling}

\section{Introduction}

Artificial insemination has attained a stage of being an indispensable and integral component of animal reproduction technologies. Its adoption has made a rapid progress in livestock production, mainly aimed at increasing milk production of bovines in many parts of the world. The population of exotic and their crossbred cattle in India has been ever increasing since last few decades; therefore demand for frozen semen of pure and crossbred dairy cattle is also increasing. However, the production and supply of frozen semen with an acceptably predictable fertility has always been a challenge because of poor fertility of cryopreserved semen [1] [2].

Cryopreservation is known to degrade the potential fertility of the sperm cells by causing death of about 50 per cent of the cells and altered characteristics of many of the remaining cells [3]. The damages generally are the consequences of mechanical and osmotic phenomenon, oxidative stress, increased membrane permeability, lipid peroxidation and subsequent membrane damage during cooling, freezing and thawing. Reactive oxygen species (ROS) and other intermediate free radicals are produced in more quantities during cooling [4]. Moreover, the levels of antioxidant defenses are decreased in bovine spermatozoa after a cycle of freezing and thawing [5]. Free oxygen radicals play a major role in lipid peroxidation as well as in protein damages that leads to cell death [6] or altered characteristics (as if the spermatozoa are capacitated or acrosome reacted) of the surviving cells [7]. Recent observations show that addition of antioxidants such as ascorbate and alfa-tocopherol to dilutors improves sperm quality by exerting protective effect on both metabolic activity and cellular viability of frozen bovine semen [8] [9].

Ascorbic acid is known to improve post-thaw motility and live percent of buffalo spermatozoa [10]. Caffeine, a metabolic stimulant enhances motility, respiration and fructolysis of epididymal and ejaculated spermatozoa of cattle and buffalo bulls [11]-[13]. It has also been reported to improve progressive motility of both fresh and preserved sperms of various species [14] [15]. Chloroquine diphosphate, a membrane stabilizer is known to stimulate the respiration and motility of fresh and aged spermatozoa in vitro [16] and to improve the post thaw quality of frozen semen [17].

Increasing evidences of beneficial effects of above compounds inspired us to investigate further in a more comprehensive way their effect on structural and functional status of the frozen semen of Holstein Friesian and crossbred (Holstein Friesian x Haryana) bull with an objective to ascertain their role, if any, in improving the potential fertility of frozen-thawed sperm.

\section{Materials and Methods}

Source of Semen: Semen samples for the experiment were collected using artificial vagina from 2 purebred Holstein Friesian and 2 crossbred (Holstein Friesian x Haryana) bulls maintained at Germ Plasm Center, Indian Veterinary Research Institute, Izatnagar, (I.V.R.I.) India. Thirty-two ejaculates (8 from each bull) were collected, processed, frozen and evaluated for various seminal characteristics.

Semen Evaluation: Each semen sample was examined for routine semen parameters (volume, color, per cent live sperm, total sperm concentration and abnormal sperm as per the standard methods described [18]. The selected ejaculates (having +3 mass activity) were divided into three parts; part one was used for dilution and freezing, part two for in vitro fertility tests [Bovine cervical mucus penetration test (BCMPT) and Hypo-osmotic swelling test (HOST)] and part three for the separation of the seminal plasma for assaying fresh stage activity of GOT, GPT, ACP and AKP. The seminal plasma was separated by centrifugation (1100 g for $20 \mathrm{~min}$.) both from fresh and frozen-thawed samples preserved in sterilized micro centrifuge tubes at $-20^{\circ} \mathrm{C}$ until the assessment of the activities of GOT, GPT, ACP and AKP were measured.

Percent Intact Acrosome: The percent acrosomal integrity of sperm was determined in fresh and postthawed semen (200 sperm cells) by preparing smears stained with Giemsa. In Figures 1, 2, 3 and 4 respectively, the denuded/lost acrosome, elongated sperm head with lost acrosome and ruffled acrosome using Giemsa stain 
have been shown. Various types of acrosome reaction with different stages with live and dead sperms are shown in plate 4 using FITC-PSA and PI stain.

Dilution and Freezing: Semen aliquot was further divided in four groups with and without additives and extended in Tris-fructose-yolk-glycerol dilutor (TFYG); [Tris Hydroxy-methyl-aminomethane-254 mM, citric acid monohydrate $-78 \mathrm{mM}$, Fructose anhydrous $-70 \mathrm{mM}$, Glycerol $-7.0 \mathrm{ml}$, Penicillin—1000 IU/ml and Streptomycin 1000 microgram/ml containing $10 \%$ egg yolk added at the time of use]. Thus prepared dilutor gave an osmolality of $\sim 320$ milli osmol. This dilutor without additives was used as a control one $\left(\mathrm{T}_{0}\right)$ and treatment dilutors were prepared as follows:

T1-TFYG + ascorbic acid $10 \mathrm{mM}$. (Merck Chemicals, Mol. Wt. 176.13)

T2-TFYG + caffeine $7 \mathrm{mM}$ (Sigma Chemicals, Mol. Wt.)

T3-TFYG + Chloroquine diphosphate $0.54 \mathrm{mM}$ (Sigma Chemicals, Mol. Wt. 319.88)

These concentrations of additives were determined based on a pilot study taken up in a comprehensive project work at our Laboratory at I.V.R.I., Izatnagar; using many other concentrations of these additives separately in TYFG (control) on post-thaw quality of semen (motility and live percent).

The semen samples were extended at $35^{\circ} \mathrm{C}$ to the extent that each ml of diluted semen contained 50 million motile spermatozoa. $0.5 \mathrm{ml}$ medium French straws for the filling of semen were used. The filled straws were kept in a bread box half filled with water at $35^{\circ} \mathrm{C}$. This box was kept in a refrigerator [freezer chamber] for $2 \mathrm{hr}$. And when the temperature of straws reached $5^{\circ} \mathrm{C}$ they were transferred to a cold cabinet $\left(4^{\circ} \mathrm{C}\right)$ where these straws were dried on a blotting paper, spread evenly over the rack and kept horizontally in liquid nitrogen vapor till the temperature of the straws reached $-120^{\circ} \mathrm{C}$. The straws were held for $10 \mathrm{~min}$. At this temperature and then plunged into the liquid nitrogen.

Post-Thaw Evaluation: After $24 \mathrm{hr}$, storage in liquid nitrogen straws were thawed at $37^{\circ} \mathrm{C}$ for $30 \mathrm{sec}$. Postthaw per cent live sperm and per cent intact acrosome were determined. A part of the post-thawed semen from all the treatment groups was used for assessment of in vitro fertilizing ability using cervical mucus penetration test and HOS test. The enzymatic activities were determined after separating the seminal plasma from the frozen semen.

\subsection{Tests for in Vitro Fertilizing Ability}

Cervical mucus penetration test: Bovine cervical mucus was collected aseptically from estrus cows brought for insemination at Institute Polyclinic. Mucus samples showing typical crystallization fern pattern and showing negative results in white side test, indicating absence of obvious infection [19] were taken for the experiment.

Non-heparinized hematocrit capillary tubes (8 cm in length) were loaded with the mucus with the help of a syringe and a rubber tube. One end of the capillary tube was sealed with hemoseal (Shandilya Chemicals, India). In a separate micro centrifuge tube, $0.5 \mathrm{~mL}$ of semen samples (fresh and post-thawed) were placed (in duplicate) and the open end of the loaded tubes was dipped in the semen vertically. After $60 \mathrm{~min}$ of incubation at $37^{\circ} \mathrm{C}$ the capillary tubes were cleaned, wiped, placed on a graduated glass slide and observed under the microscope for the distance traveled in mucus by the vanguard spermatozoa. The semen samples were graded on the basis of the distance traveled by the vanguard spermatozoa in 60 min as follows [20].

Excellent more than $30 \mathrm{~mm}$.

Good more than $20 \mathrm{~mm}$ but less than $30 \mathrm{~mm}$.

Medium 12 to $20 \mathrm{~mm}$.

Poor less than $12 \mathrm{~mm}$.

Hypo-osmotic swelling test (HOST): In micro-tubes containing $1.0 \mathrm{ml}$ of hypo-osmotic solution (sod. citrate $25 \mathrm{mM}$, fructose $75 \mathrm{mM}$ added to $100 \mathrm{~mL}$ double distilled water with an osmolality of approximately $100 \mathrm{mM}$ ) $0.1 \mathrm{~mL}$ of fresh and frozen-thawed semen samples were incubated at $37^{\circ} \mathrm{C}$ for $60 \mathrm{~min}$. After incubation, a small drop from the bottom of the tube was placed on a slide, covered with a coverslip and examined for different swelling pattern as follows [21]:

Pattern A: no swelling, no membrane reaction

Pattern B: swelling of the tip of the sperm tail

Pattern C: different types of hairpin like swellings of the mid piece

Pattern D: complete swelling of the tail region

A total of 200 cells were counted. The sperm cells showing Pattern B, C and D were considered positive for the HOST test. 


\subsection{Enzymes Assay}

Seminal plasma from fresh and frozen-thawed samples was separated by centrifugation at $1100 \mathrm{~g}$ for $20 \mathrm{~min}$. and preserved at $-20^{\circ} \mathrm{C}$ till the enzyme activity was determined. The activity of glutamic oxaloacetic and pyruvic tansaminases (GOT and GPT) was estimated according to the method described by [22]. The activity of alkaline phosphatase (AKP) and acid phosphatase (ACP) was determined following the method of [23] using Qualigen's Kit.

\subsection{Statistical Analysis}

Means and standard errors were calculated. Analysis of variance (ANOVA) was used for comparing the effects of different factors (bulls, breeds, treatments etc.) and means were compared using Duncan's Multiple Range Test (DMRT) as per [24] on Wipro-Pentium computer of the Institute.

\section{Results}

\subsection{Fresh Semen Quality}

The mean $( \pm$ SE) cytomorphological seminal characteristics and functional attributes of fresh semen of both Holstein Friesian (HF) and crossbred bulls are presented in Table 1. The crossbred bull semen had a significantly lower mass activity ( $\mathrm{P} \leq 0.01)$, individual motility ( $\mathrm{P} \leq 0.01)$, sperm penetration distance in cervical mucus $(\mathrm{P} \leq 0.01)$, per cent HOS positive sperm $(\mathrm{P} \leq 0.01)$ and plasma GOT level $(\mathrm{P} \leq 0.01)$ and higher abnormal sperm per cent $(\mathrm{P} \leq 0.01)$ than those of HF bull.

Volume of semen differed significantly $(\mathrm{P}<0.01)$ between two HF bulls. Mass motility $(0-5$ scale) differed significantly $(\mathrm{P}<0.01)$ between two breeds. The per cent individual motility differed significantly $(\mathrm{P}<0.01)$ between 2 HFxH $(\mathrm{P}<0.01)$ and 2 HF bulls $(\mathrm{P}<0.05)$. Similarly the per cent live sperm differed significantly between the two breeds $(\mathrm{P}<0.01)$ and between two HF bulls $(\mathrm{P}<0.05)$. A significant difference $(\mathrm{P}<0.01)$ in the total per cent abnormal sperm was also found between 2 HF bulls $(\mathrm{P}<0.01)$. The population of sperm with intact acrosome differed significantly $(\mathrm{P}<0.01)$ between breeds and between $2 \mathrm{HF}$ bulls $(\mathrm{P}<0.05)$. Besides these seminal characteristics the total sperm concentration per unit did not differ between breeds and bulls (Table 1).

Analysis of variance revealed a significant difference $(\mathrm{P}<0.01)$ in the GOT activity of fresh semen between

Table 1. Cyto-morphological and functional attributes (Mean \pm SE) of fresh semen of HF and crossbred bulls.

\begin{tabular}{ccc}
\hline Seminal characteristics & HF bulls & Crossbred bulls \\
\hline Mass motility (\%) & $4.0 \pm 0.4^{\mathrm{a}}$ & $3.0 \pm 0.2^{\mathrm{b}}$ \\
Volume (ml) & $4.9 \pm 1.9$ & $5.6 \pm 1.3$ \\
Individual motility (\%) & $82.2 \pm 3.6^{\mathrm{b}}$ & $78.1 \pm 6.3^{\mathrm{b}}$ \\
Live sperm count (\%) & $87.4 \pm 1.4$ & $84.1 \pm 2.3$ \\
Total abnormal sperm count (\%) & $10.1 \pm 1.5^{\mathrm{B}}$ & $12.6 \pm 2.3^{\mathrm{A}}$ \\
Intact acrosome (\%) & $89.9 \pm 1$. & $87.4 \pm 2.3$ \\
Sperm concentration (millions/ml) & $917.5 \pm 127.9$ & $968.1 \pm 111.3$ \\
BCMPT distance (mm) & $45.1 \pm 3.3^{\mathrm{a}}$ & $39.9 \pm 2.9^{\mathrm{b}}$ \\
HOST positive sperms (\%) & $69.4 \pm 2.8^{\mathrm{a}}$ & $64.1 \pm 2.3^{\mathrm{b}}$ \\
GOT (micro mole/L) & $55.8 \pm 20.2^{\mathrm{a}}$ & $43.4 \pm 21.9^{\mathrm{b}}$ \\
GPT (micro mole/L) & $15.8 \pm 5.7$ & $14.3 \pm 4.6$ \\
AKP (KAU/100ml) & $219.0 \pm 101.0$ & $223.1 \pm 100.9$ \\
ACP (KAU/100ml) & $298.4 \pm 102.4$ & $290.3 \pm 117.0$ \\
\hline
\end{tabular}

Means bearing superscript a, b differ significantly $(\mathrm{P}<0.01)$. Means bearing superscript A, B differ significantly $(\mathrm{P}<0.05)$. 
the 2 breeds, but within the breeds between the bulls the difference was non-significant (Table 2). The GPT activity, however, did not differ significantly between breeds and bulls. The AKP activity in the fresh seminal plasma did not differ between the breeds but it differed significantly $(\mathrm{P}<0.05)$ between 2 HFxH bulls. No variation in the ACP activity in the fresh seminal plasma of either between breeds or between bulls within the breeds was found.

Comparison of distance traveled by vanguard sperm (the sperm moving farthest distance) in the cervical mucus, by the sperm of both the breeds revealed that the SPD varied significantly $(\mathrm{P}<0.01)$ between breeds and bulls. The HF sperm traveled a longer distance than HFxH sperm. The per cent total sperm responding to hypoosmotic swelling test was significantly $(\mathrm{P}<0.01)$ higher for HF bull semen than HFxH semen. This parameter also differed significantly $(\mathrm{P}<0.01)$ between the $2 \mathrm{HFxH}$ bulls.

\subsection{Post-Thaw Quality}

Analysis of data for the pooled means of various seminal characteristics of HF and HFxH bulls after freezing thawing using DMRT Test revealed that post-thaw motility between the two breeds of bulls did not differ significantly (Table 2) but within the breed between bulls it differed significantly $(\mathrm{P}<0.01$; Table 3 ).

The pooled data on various seminal characteristics showing the effect of different additives are presented in Table 4. Perusal of this data indicates that almost all the parameters which are responsible for adjudging the quality of semen were significantly $(\mathrm{P}<0.05)$ higher in the treatment group of ascorbic acid than other two additives. Similarly the leakage of enzymes was significantly low in this group of ascorbic acid than other two additives (Table 4). More interestingly it was noted that as compared to control group, in the caffeine treated group the enzymes leakage was higher (although not significantly) but in the ascorbic acid and chloroquine

Table 2. Cytomorphological and functional attributes (Mean \pm SE) of frozen thawed semen of HF and crossbred bulls.

\begin{tabular}{ccc}
\hline Seminal characteristics & HF bulls & Crossbred bulls \\
\hline Post-thaw motility \% & $30.31 \pm 1.25$ & $28.1 \pm 1.4$ \\
Post-thaw livability \% & $55.5 \pm 1.0^{\mathrm{a}}$ & $45.9 \pm 1.3^{\mathrm{b}}$ \\
Post-thaw intact acrosome (\%) & $70.5 \pm 0.8^{\mathrm{a}}$ & $67.7 \pm 1.2^{\mathrm{b}}$ \\
Post-thaw BCMPT distance (mm) & $19.69 \pm 0.47$ & $18.4 \pm 0.6$ \\
Post-thaw HOST positives sperms (\%) & $21.8 \pm 0.5$ & $21.0 \pm 0.6$ \\
Post-thaw GOT (micro mole/L) & $417.5 \pm 26.8^{\mathrm{a}}$ & $350.6 \pm 20.7^{\mathrm{b}}$ \\
Post-thaw GPT (micro mole/L) & $197.5 \pm 20.3$ & $208.7 \pm 20.5$ \\
Post-thaw AKP (KAU/100ml) & $392.1 \pm 40.4$ & $375.7 \pm 42.8$ \\
Post-thaw ACP (KAU/100ml) & $473.2 \pm 49.4$ & $556.8 \pm 71.8$ \\
\hline
\end{tabular}

The means bearing superscript a, b differ significantly $(\mathrm{P}<0.01)$.

Table 3. Mean sum of squares showing influence of breeds, bulls and treatments on cytomorphological and functional characteristics and seminal plasma enzymes level of frozen-thawed spermatozoa.

\begin{tabular}{|c|c|c|c|c|c|c|c|c|c|}
\hline $\begin{array}{l}\text { Sources of } \\
\text { variation }\end{array}$ & $\begin{array}{c}\text { Motility } \\
\%\end{array}$ & $\begin{array}{c}\text { Livability } \\
\%\end{array}$ & $\begin{array}{c}\text { Intact } \\
\text { acrosome \% }\end{array}$ & $\begin{array}{c}\text { BCMPT } \\
\text { o distance }(\mathrm{mm})\end{array}$ & $\begin{array}{c}\text { Host } \\
\text { response (\%) }\end{array}$ & $\begin{array}{l}\text { GOT micro } \\
\mathrm{mol} / \mathrm{L}\end{array}$ & $\begin{array}{l}\text { GPT micro } \\
\mathrm{mol} / \mathrm{L}\end{array}$ & $\begin{array}{l}\text { AKP KAU/ } \\
100 \mathrm{~mL}\end{array}$ & $\begin{array}{l}\text { ACP KAU/ } \\
100 \mathrm{~mL}\end{array}$ \\
\hline $\begin{array}{l}\text { Between } \\
\text { breeds }\end{array}$ & $361.13^{* *}$ & $46.32^{*}$ & $187.70^{* *}$ & $50.00^{* *}$ & $43.95^{* *}$ & $81759.57^{* *}$ & 3003.13 & 4572.67 & 71775.50 \\
\hline Between treatments & $1897.07^{* *}$ & $1673.07^{* *}$ & $690.07^{* *}$ & $471.55^{* *}$ & $440.51^{* *}$ & $90245.51^{* *}$ & $46780.21^{* *}$ & $67780.92^{* *}$ & 103525.39 \\
\hline Between HF bulls & $306.25^{* *}$ & $42.25^{*}$ & $126.56^{* *}$ & $66.02^{* *}$ & $118.27^{* *}$ & $130953.52^{* *}$ & 756.25 & 42473.60 & 160718.81 \\
\hline Between FxH bulls & $244.14^{* *}$ & $395.02^{* *}$ & $365.77^{* *}$ & $58.14^{* *}$ & $36.00^{* *}$ & 76.56 & $600025.00^{* *}$ & 75254.89 & 143750.93 \\
\hline Breed $\mathrm{x}$ treatment & 11.65 & 22.55 & $1.99^{*}$ & 5.23 & 3.28 & 1021.03 & 1792.71 & 6580.71 & 1397.30 \\
\hline
\end{tabular}

${ }^{* *}$ Significant $(\mathrm{P}<0.01)$; ${ }^{*}$ Significant $(\mathrm{P}<0.01)$. 
group the enzyme leakage was less than the control. This table further reveals that the increase in the post-thaw motility was almost $8 \%$ with ascorbic acid, $10 \%$ with caffeine and $7 \%$ with chloroquine. The increase in the percent post-thaw live sperm was $17 \%, 11 \%$ and $8 \%$, respectively for ascorbic acid, caffeine and chloroquine. The per cent increase in the intact acrosome was about $11 \%, 5 \%$ and $3 \%$ in presence of ascorbic acid, caffeine and chloroquine, respectively. The sperm traveled an increased distance of about $9 \%, 5 \%$ and $4 \%$ in presence of ascorbic acid, caffeine and chloroquine, respectively. The response of sperm cells to HOST was also on the similar lines and the increased per cent for ascorbic acid, caffeine and chloroquine, respectively were $9 \%, 5 \%$ and $4 \%$.

\subsection{Correlation among Semen Parameters (Post-Thawed)}

Post-thaw motility showed a strong positive correlation with the parameters like livability $(r=0.86, P<0.01)$, intact acrosome $(r=0.74, \mathrm{P}<0.01)$, SPD $(r=0.73, \mathrm{P}<0.01)$ and HOST response $(\mathrm{r}=0.72, \mathrm{P}<0.01)$ (Table 5) as expected. This relationship of motility along with the positive correlation of post-thaw intact acrosome (PTIA) with SPD $(r=0.67, \mathrm{P}<0.01)$ and HOST response $(r=0.66, \mathrm{P}<0.01)$ supports the approach of using three independent parameters of sperm structure and function as an indicator of cryopreservation success in examining the quality of frozen semen. The AKP was also positively correlated with ACP value $(r=0.88, P<0.01)$.

Table 4. Cytomorphological, functional and some biochemical attributes (Mean \pm SE) of frozen-thawed semen irrespective of breed and bulls.

\begin{tabular}{|c|c|c|c|c|}
\hline Seminal characteristics & Control & Ascorbic acid & Caffeine & Chloroquine \\
\hline Motility (\%) & $29.2 \pm 5.2^{\mathrm{c}}$ & $47.8 \pm 5.8^{\mathrm{a}}$ & $38.9 \pm 4.7^{\mathrm{b}}$ & $36.1 \pm 5.0^{b}$ \\
\hline Livability (\%) & $55.2 \pm 4.6^{\mathrm{c}}$ & $72.6 \pm 3.1^{\mathrm{a}}$ & $66.6 \pm 3.6^{b}$ & $63.1 \pm 4.2^{b}$ \\
\hline Intact acrosome (\%) & $69.2 \pm 4.4^{\mathrm{c}}$ & $80.3 \pm 3.5^{\mathrm{a}}$ & $74.1 \pm 3.9^{b}$ & $72.8 \pm 3.9^{b}$ \\
\hline BCMPT distance (mm) & $19.0 \pm 2.2^{c}$ & $28.3 \pm 2.4^{\mathrm{a}}$ & $24.7 \pm 2.3^{b}$ & $23.6 \pm 2.6^{b}$ \\
\hline HOS positive sperms (\%) & $21.4 \pm 2.0^{c}$ & $30.4 \pm 3.0^{\mathrm{a}}$ & $26.8 \pm 2.4^{b}$ & $25.7 \pm 2.4^{b}$ \\
\hline GOT (micro mole/l) & $384.0 \pm 100.2^{\mathrm{a}}$ & $285.1 \pm 86.4^{\mathrm{c}}$ & $399.6 \pm 106.6^{\mathrm{a}}$ & $323.4 \pm 87.6^{b}$ \\
\hline GPT (micro mole/l) & $203.1 \pm 80.4^{\mathrm{a}}$ & $134.6 \pm 55.4^{\mathrm{b}}$ & $214.0 \pm 102.3^{\mathrm{a}}$ & $153.7 \pm 71.0^{b}$ \\
\hline AKP (KAU/100ml) & $383.9 \pm 164.0^{\mathrm{b}}$ & $314.6 \pm 141.2^{\mathrm{b}}$ & $420.4 \pm 186.1^{\mathrm{a}}$ & $345.7 \pm 146.7^{\mathrm{b}}$ \\
\hline ACP (KAU/100ml) & $515.0 \pm 246.1$ & $432.1 \pm 195.3$ & $561.4 \pm 250.3$ & $464.1 \pm 181.7$ \\
\hline
\end{tabular}

Means bearing different superscripts $\left({ }^{\mathrm{a}, \mathrm{b}, \mathrm{c}}\right)$ in a row are significantly different $(\mathrm{P}<0.05)$, separately for each treatment.

Table 5. Correlation coefficients among cytomorpological, functional and biochemical attributes of post thaw semen in tris dilutor (HF and FXH pooled) without additives.

\begin{tabular}{|c|c|c|c|c|c|c|c|c|}
\hline Seminal characteristics & PTM & PTL & PTIA & PT-SPD & PT HOST & PT-GOT & PT-GPT & PT-AKP \\
\hline Motility \% (PTM) & 1.00 & & & & & & & \\
\hline Livability \% (PTL) & $0.86^{* *}$ & 1.00 & & & & & & \\
\hline Intact acrosome \% (PTIA) & $0.74^{* *}$ & $0.65^{* *}$ & 1.00 & & & & & \\
\hline BCMPT dist. mm. (PT SPD) & $0.73^{* *}$ & $0.69^{* *}$ & $0.67^{* *}$ & 1.00 & & & & \\
\hline Host Positive \% (PT HOST) & $0.72^{* *}$ & $0.71^{* *}$ & $0.66^{* *}$ & $0.92^{* *}$ & 1.00 & & & \\
\hline GOT Level umole/L & 0.13 & 0.02 & 0.24 & 0.26 & 0.18 & 1.00 & & \\
\hline GPT level umole/L & -0.02 & -0.12 & 0.06 & 0.20 & 0.17 & 0.18 & 1.00 & \\
\hline AKP level KAU/100mL & 0.28 & 0.10 & 0.09 & -0.02 & 0.08 & -0.14 & -0.09 & 1.00 \\
\hline ACP level KAU/100mL & 0.03 & -0.07 & -0.02 & -0.24 & -0.13 & $-0.45^{* *}$ & -0.11 & $0.76^{* *}$ \\
\hline
\end{tabular}

PT = Post-Thaw, KAU = King and Armstrong Unit. ${ }^{*}$ Significant at $5 \%$ level; ${ }^{* *}$ Significant at $1 \%$ level. 
In general, the trend of correlations of seminal parameters, even after addition of these substances in the dilutor (i.e. with treatments) remained the same as in control dilutor (presented in Table 4), but the values differed to some extent. The post-thaw motility (PTM) was significantly positively correlated with post-thaw livability (PTL) ( $r=0.86,0.57,0.59$ and 0.59 for $\mathrm{T}_{0}, \mathrm{~T}_{1}, \mathrm{~T}_{2}$ and $\mathrm{T}_{3}$ treatments respectively), PTIA $(\mathrm{r}=0.74,0.78,0.73$ and 0.58 for $\mathrm{T}_{0}, \mathrm{~T}_{1}, \mathrm{~T}_{2}$ and $\mathrm{T}_{3}$ treatments respectively) and $\mathrm{SPD}$ value $\left(\mathrm{r}=0.73,0.60,0.58\right.$ and 0.45 for $\mathrm{T}_{0}, \mathrm{~T}_{1}$, $\mathrm{T}_{2}$ and $\mathrm{T}_{3}$ treatments respectively). PTM was also significantly positively correlated with HOST response $[\mathrm{r}=$ 0.72, 0.67 and $0.55(\mathrm{P}<0.01)$ for $\mathrm{T}_{0}, \mathrm{~T}_{1}, \mathrm{~T}_{2}$ and $\mathrm{r}=0.38(\mathrm{P}<0.05)$ for $\mathrm{T}_{3}$ group].

\section{Discussion}

Crossbred bulls of different genetic make-up are usually reported to have different semen characteristics [25][28]. Total sperm abnormalities were higher in crossbred bull than HF bull semen which had also been reported earlier [29]. The perpetuation of this problem is inherent which can be attributed to the fact that even in well organized dairy farms, sperm parameters as a trait receive less priority in the selection criteria for the cross breeding of animals under Indian management conditions. The differences in seminal cyto-morphological characteristics between the two breeds of bulls are normally expected and our values are in agreement with the earlier reports from bulls of different genetic make-up [26]-[28]. These findings confirm the inferiority of crossbred bull semen in many respects as compared to semen from pure bred bulls.

Perusal of data of the frozen thawed semen from these bulls revealed that post-thaw parameters such as motility, livability, intact acrosome, BCMPT distance and percent HOST positive sperm were lower than desirable (Table 2). On these samples (control) intact acrosome per cent was significantly lower in crossbred (HFxH) bulls than that of pure HF bulls. Acrosomal changes are highly correlated with fertility of frozen-thawed semen [30] and are simpler and easier method to evaluate the effect of many variables on the spermatozoa. A significant relationship between sperm motility and acrosomal integrity with fertility has been reported [31]. However, Cumming [32] observed that despite the effect that the bulls could be classified into three statistically significant groups according to their non return rates, there was no significant correlation between the percentage of intact acrosome and the non return rates of bulls. In previous report on cattle and buffalo bulls [33] acrosomal intactness is reported to be significantly affected by the dilutor composition in frozen semen. Possibly this explains our findings of differences in the per cent intact acrosome in presence of different additives, which definitely altered the composition of dilutor. Ascorbic acid was superior in maintaining better acrosomal intactness in frozen samples than caffeine and chloroquine.

Variation in post-thaw per cent intact acrosome (PTIA) could be due to differences in response of the cell membranes to freezing that can be related to the defects in spermatogenesis [34]. A decline in the intact acrosome percent in the frozen thawed spermatozoa has also been reported earlier in cattle bull [29] [35] [36] and buffalo bull semen [33] [37].

The leakage of enzymes from sperm cell into the seminal plasma was very severe. Compared to fresh samples more than 8 fold increases in enzymatic activities of the GOT and GPT and almost 2 folds of ACP and AKP in the frozen-thawed seminal plasma was observed. This increase in enzymatic activity in the frozen-thawed seminal plasma indicates increased cell membrane permeability and damages to the sperm cells during the process of freezing and thawing. However, minimum leakage of these enzymes during the process of freezingthawing in presence of ascorbic acid than caffeine and chloroquine suggests that the detrimental actions of ROS were prevented especially on the membrane structure by ascorbic acid.

Assessment of post-thaw semen based on cytomorphology, sperm function (motility, HOST response and SPD and some enzymatic constituents; phosphatases and transminases) in the seminal plasma after the addition of ascorbic acid, caffeine or chloroquine indicated that there was a significant improvement in the quality of semen both in HF and crossbred bull semen. Ascorbic acid when added, in the semen, is known to enhance motility of bull sperm [40] and buffalo sperms under refrigerated temperature for 120 hours increase post-thaw sperm motility and livability [38]. However, Sanchez-Partida et al. [39] observed no effect on motility after addition of ascorbic acid at the concentration of $25 \mathrm{mM}$. Addition of ascorbic acid resulted in about $18 \%$ increase in the post-thaw motility in the present study. Improvement in the post-thaw motility after adding ascorbic acid in the dilutor has been reported [40]. The better effect of ascorbic acid than caffeine and chloroquine, in the present study, might be because of low sperm damage in presence of ascorbic acid as it has been reported to protect the spermatozoa from the peroxidase damage [41]. 
Reactive oxygen species (ROS) are continuously produced in the ejaculates by spermatozoa and accompanying leukocytes [42] [43] impairing spermatozoal metabolism and affecting their fertilizing ability [44]. Any substance present in the dilutor, which can prevent the action of ROS, may improve the quality of semen. Ascorbic acid protects spermatozoa from free radical damage and improves their motility and viability [45]. On these lines the better effect of ascorbic acid in improving the post-thaw quality of frozen semen of both the breeds in the present study are justifiable.

One of the objectives of present study was to find out the effects of the additives on both HF and crossbred bull semen and see if there was any interaction between the breeds and the treatment. There was no any interaction between the breed and additives for all the investigated parameters (Table 3). The analysis of data of all the four bulls pooled together (Table 4) revealed that incorporation of all the three additives resulted in significantly higher $(\mathrm{P}<0.01)$ values for percent motility, livability, intact acrosome, BCMPT distance and HOST response than that of control; ascorbic acid showing the best and caffeine and chloroquine moderate improvement in the quality of the frozen semen. The effect of chloroquine and caffeine is comparable for all the parameters. Caffeine inhibits cAMP and cGMP which appears to be responsible for enhancing sperm motility [11]. cAMP acts directly on the plasma membrane of sperm cells and thereby regulates the exchange of inorganic phosphate and calcium ions resulting in improvement in sperm motility and integrity [34]. Incorporation of caffeine also improved the per cent post-thaw intact acrosome in present study, but the values were lower than ascorbic acid. Since considerable damage is inflicted on the sperm plasma membrane during cryo-storage, caffeine may compensate for this damage by stimulating the activity of an outwardly directed plasma membrane calcium pump through the mediation of cAMP [34]. However, prevention of damages to plasma membrane in caffeine group was poor than ascorbic acid and chloroquine (Table 4), possibly because caffeine is a stimulant and once spermatozoal metabolism is increased in presence of caffeine such results are expected.

The incorporation of chloroquine in the extender has been found to increase sperm viability after cryopreservation [17]. However, chloroquine did not improve post-thaw motility of boar semen [46]. The findings that chloroquine diphosphate might be useful to prevent the leakage of vital enzymes [47] support our results. In presence of chloroquine diphosphate in the dilutor although an increase in post-thaw motility in the present study, as well as reported earlier [16], was recorded but this increase was less as compared to ascorbic acid and caffeine. [16] reported an increase in the post-thaw motility after incorporating chloroquine. Chloroquine a membrane stabilizer and anti-inflammatory agent is reported to stimulate respiration and motility [16] through directly or indirectly acting on adenyle cyclase system.

Incorporation of additives resulted in lower enzyme leakage in the extracellular fluid as evident from reduced activities of GOT, GPT, AKP and ACP in frozen-thawed seminal plasma of the treatment group than that of in the control group (Table 4). In the seminal plasma minimum enzymatic activities were observed in the presence of ascorbic acid followed by chloroquine and caffeine when compared with the control group. The difference in values for transaminaes (GPT and GOT) for caffeine added and control groups was non-significant but the former had a slightly higher value. The leakage of and ACP was also maximum in the caffeine added group implying that enhanced metabolic activity during cooling, freezing and post-thawing causes the membrane to be more permeable and prone to damages.

It is now known that cryopreservation induces formation of reactive oxygen species (ROS) that are detrimental to spermatozoa [48] [49]. Ascorbic acid through its reducing properties [50] might have minimized the probable oxidative damages to the membranes by ROS thus preventing to some extent the enzyme leakage.

It is apparent from the study that ascorbic acid, chloroquine diphosphate and caffeine treated dilutor altered the structural and functional status of the frozen spermatozoa when compared with that of control. All the three compounds used as additives produced desirable effect on frozen thawed spermatozoa by increasing live, motile sperm and HOS responsive cell percentage and by reducing the enzyme leakage from the sperm cells during cryopreservation. Among the three compounds ascorbic acid brought the best desirable changes followed by chloroquine di-phosphate. It could, therefore, be concluded that addition of ascorbic acid at the concentration of $10 \mathrm{mM}$ exerts beneficial effect and help improve the quality of frozen semen of pure HF and crossbred (HFxH) bulls.

\section{Acknowledgements}

The authors thank the Director and Head Division of Animal Reproduction and to Sri G.S. Bisht Senior Scientist, 
Computer Section of the Institute for the help.

\section{References}

[1] Roy, D.J., Biswas, J.C., Bandopadhayay, S.K. and Bhat, P.N. (1975) Study on the Freezability of Spermatozoon in Three Genetic Groups of Crossbred Bulls. Indian Journal of Dairy Science, 13, 112-116.

[2] Verma, N.K. (1997) Cryopreservation Studies of Crossbred Bull Semen with Special Reference to Buffers, Membrane Stabilizer and Seminal Enzymes. M.V.Sc. Thesis, Indian Veterinary Research Institute, Izatnagar.

[3] Watson, P.F. (1995) Recent Development and Concepts in the Cryopreservation of Spermatozoa and the Assessment of Their Post-Thaw Function. Reproduction, Fertility and Development, 7, 871-891. http://dx.doi.org/10.1071/RD9950871

[4] Wang, W.H., Niwa, K. and Okuda, K. (1991) In Vitro Penetration of Pig Oocytes Matured in Culture by FrozenThawed Ejaculated Spermatozoa. Journal of Reproduction and Fertility, 93, 491-496. http://dx.doi.org/10.1530/jrf.0.0930491

[5] Belodeau, J.F. Chaterjee, S., Srard, M.A. and Gagnon, C. (2000) Level of Antioxidant Defenses Are Decreased in Bovine Spermatozoa after a Cycle of Freezing and Thawing. Molecular Reproduction and Development, 55, 282-288. http://dx.doi.org/10.1002/(SICI)1098-2795(200003)55:3<282::AID-MRD6>3.0.CO;2-7

[6] Farber, J.L., Kyle, M.E. and Cleman, J.B. (1990) Mechanism of Cell Injury by Activated Oxygen Species. Laboratory Investigation, 62, 670-679.

[7] Bailey, J.L., Bilodeau, J.F. and Cormier, N. (2000) Semen Cryopreservation in Domestic Animals : A Damaging and Capacitating Phenomenon. Journal of Andrology, 21, 1-6.

[8] Beconi, M.T., Francia, C.R., Mora, N.G. and Affranchino, M.A. (1993) Effect of Natural Antioxidants on SOD Activity in Bovine Sperm. Biochemistry International, 23, 545-553.

[9] O’Flaherty, C., Becani, M. and Berlegni, N. (1997) Effect of Natural Antioxidants, Super Oxide Demitasse and Hyper Oxide on Cap Citation of Frozen Thawed Bull Sperm. Andrologia, 29, 269-275. http://dx.doi.org/10.1111/j.1439-0272.1997.tb00481.x

[10] Singh, B., Chand, D., Yadav, N.K. and Singh, P. (1995) Effect of Vitamins C Addition in the Diluent on the Quality of Refrigerated Murrah Buffalo Bull (Bubalus bubalis) Semen. Indian Journal of Animal Reproduction, 29, 79-84.

[11] Garbers, D.L., First, N.L. and Lardy, H.A. (1973) The Stimualation of Bovine Epididymal Sperm Metabolism by Cyclic Nucleotidase Inhibitors. Biology of Reproduction, 8, 589-598.

[12] Garbers, D.L., First, N.L., Sullivan, J.J. and Lardy, H.A. (1971) Stimulation and Maintenance of Ejaculated Bovine Spermatozoal Respiration and Motility by Caffeine. Biology of Reproduction, 5, 335-339.

[13] Fattouh, El-S.M., Seida, A.A., Nasir, M.T. and Abdou-Ahmed, M.M. (1985) Effect of Caffeine on the Motility of Ejaculated and Epididymal Buffalo Spermatozoa. Veterinary Medical Journal, 33, 261-271.

[14] Schill, W.B. (1982) Therapie der, Idiopathischen Astheno und Oligozoospermite mit Penroxifylline Fortschr. Med, 100, 696-700.

[15] Norman, C. and Gombe, S. (1975) Stimulatory Effect of the Lysosomal Stabilizer, Chloroquine, on the Respiration and Motility of Fresh and Aged Spermatozoa. Journal of Reproduction and Fertility, 44, 481-486. http://dx.doi.org/10.1530/jrf.0.0440481

[16] Schilen, N., Paz, G., Homonnai, Z.T. and Schoenbaun, M. (1978) The Effect of Caffeine on Guinea Pig Epididymal Spermatozoa: Motility and Fertilizing Capacity. International Journal of Andrology, 1, 416-423. http://dx.doi.org/10.1111/j.1365-2605.1978.tb00613.x

[17] Sidhu, S.S., Pangawakar, G.R. and Chaudshry, R.K. (1996) Effect of Some Additives on the Release of Enzymes from Buffalo Spermatozoa during Cryopreservation. Indian Veterinary Journal, 73, 154-158.

[18] Salisbury, G.W., Van Demark, N.L. and Lodge, J.R. (1985) Physiology of Reproduction and Artificial Insemination of Cattle. 2nd Edition, CBS Publishers and Distributors, Shadara.

[19] Pateria, A.K. and Rawal, C.V.S. (1990) White Side Test for Subclinical Metritis in Buffaloes. Indian Journal of Animal Reproduction, 11, 142-144.

[20] Matousek, J., Riha, J., Sarsen, V., Veseldky, L. and Londa, F. (1989) Penetration of Cervical Mucus and Other Body Fluids by Bull Sperm in Capillary Tubes. Animal Reproduction Science, 18, 161-166. http://dx.doi.org/10.1016/0378-4320(89)90018-3

[21] Prasad, J.K., Kumar, S., Mohan, G., Agarwal, S.K. and Shankar, U. (1999) Simple Modified Method for Cervical Mucus Penetration Test for Quality Assessment of Bull Semen. The Indian Journal of Animal Sciences, 69, 103-105.

[22] Reitman, S. and Frankel, S. (1957) A Calorimetric Method for the Determination of Serum Glutamic Oxaloacetic 
Transaminase and Serum Glutamic Pyruvic Transaminase. American Journal of Clinical Pathology, 28, 56-60.

[23] King, E.J. and Armstrong, A.R. (1934) Practical Clinical Biochemistry. 3rd Edition, Inter Science Books Inc., New York.

[24] Steel, R.G.D. and Torrie, J. (1981) Principles and Procedures of Statistics. A biometric Approach. 2nd Edition, Mc Graw Hill International Book Co., Singapore City.

[25] Patel, K.V., Dhami, J.A. and Kodagali, S.B. (1989) Seminal Characteristics and Their Interrelationships in Kankrej x Jersey and Kankrej x Holstein Friesian Crossbred Bulls. Indian Veterinary Journal, 66, 737-743.

[26] Pathak, N., Benjamin, B.R., Mohan, G. and Sahni, K.L. (1990) Libido in Relation to Other Reproductive Traits among Crossbred Bulls. The Indian Journal of Animal Sciences, 60, 52-54.

[27] Singh, D.M. and Pangawakar, G.R. (1990) Studies on Some Characteristics of Exotic and Crossbred Bull Spermatozoa. Indian Journal of Animal Reproduction, 11, 92-95.

[28] Prasad, J.K. (1997) Studies on Enzymatic Changes and in Vitro Fertility Tests in Relation to Cryopreservation of Crossbred Bull Semen. M.V.Sc. Thesis, IVRI, Izatnagar.

[29] Biswas, J.C., Raina, B.L., Kumar, R. and Bhat, P.N. (1978) Studies on Live and Abnormal Spermatozoa in Crossbred Bull. Indian Journal of Animal Health, 15, 129-132.

[30] Saacke, R.G. and White, J.M. (1972) Semen Quality Tests and Their Relationship to Fertility. NAAB Tech.Conf.A.I. and Reproduction.

[31] Kjoestad, H., Ropstad, E. and Berg, A.K. (1993) Evaluation of Spermatozological Parameters Used to Predict the Fertility of Frozen Bull Semen. Acta Veterinaria Scandinavica, 34, 299-303.

[32] Cumming, I.R. (1995) Suitability of Intact Acrosome Method for Prediction of Fertility in Bovine Artificial Insemination. Veterinary Record, 136, 289-291. http://dx.doi.org/10.1136/vr.136.12.289

[33] Kumar, D. (1995) Studies on the Effect of Follicular Fluid and Certain Additives on Preservability of Buffalo Spermatozoa. M.V.Sc. Thesis, IVRI, Izatnagar.

[34] Mann, T. and Lutwalk-Mann, C. (1981) Male Reproductive Function and Semen. Springer-Verlag, Berlin, Heidetberg, New York.

[35] Gilbert, R.G. and Almquest, J.O. (1978) Effect of Processing Procedures on Post-Thaw Acrosomal Retention and Motility of Bovine Spermatozoa Packages in $0.3 \mathrm{~m}$ Straws at Room Temperature. Journal of Animal Science, 46, 225.

[36] Workmeister, A.V.H. (1978) Spermatogenic Study of Bull Ejaculates during Deep Freeze Preservation with Particular Reference to Acrosome Morphology and Heat Resistance Tests. Animal Breeding Abstracts, 46, 5447.

[37] Ganguli, N.C. (1979) Seemingly Silent Seminal Plasma. Indian Dairyman, 31, 879-882

[38] Singh, B., Singh, D., Singh, P., Yadav, N.K., Singh, B. and Chand, D. (1996) Effect of Vitamin C Addition in the Diluent of the Quality of Deep Frozen Muraah Buffalo Bull (Bubalus Bubalis) Semen. International Journal of Animal Sciences, 11, 131-132.

[39] Sanchez-Partida, L.G., Setchell, B.P. and Maxwell, W.M.C. (1997) Epididymal Compounds and Antioxidants in Diluents for Frozen Storage of Ram Spermatozoa. Reproduction, Fertility and Development, 9, 689-696. http://dx.doi.org/10.1071/R97045

[40] Stoyanov, T. and Zagorski, D. (1990) Effect of Some Therapeutic Substances Added to Thawing Solution for Bull Semen on Semen Quality. Veterinarna Sbrika, 88, 40-43.

[41] Jones, R. and Mann, T. (1977) Damage to Ram Spermatozoa by Peroxidase of Endogenous Phospholipids. Fertility and Sterility, 50, 261-268.

[42] Aitkin, R.J. (1994) A Free Radical Theory of Male Infertility. Reproduction, Fertility and Development, 6, 19-23. http://dx.doi.org/10.1071/RD9940019

[43] Aitkin, R.J. (1995) Free Radical Lipid Per-Oxidation and Sperm Production. Reproduction, Fertility and Development, 7, 659-668. http://dx.doi.org/10.1071/RD9950659

[44] Cummins, J.M., Jaquir, A.M. and Kam, R. (1994) Molecular Biology of Human Male Infertility: Links with Aging, Mitochondrial Genetics and Oxidative Stress. Molecular Reproduction and Development, 37, 345-362. http://dx.doi.org/10.1002/mrd.1080370314

[45] Verma, A. and Kanwar, K.C. (1998) Human Sperm Motility and Lipid Peroxidation in Different Ascorbic Acid Concentrations: An in Vitro Analysis. Andrologia, 30, 325-329. http://dx.doi.org/10.1111/j.1439-0272.1998.tb01178.x

[46] Wemheuer, W. (1988) Improvement of Semen Freezing in Pigs (Deep Freezing, Analysis and Use of Additives).Thesis, Fachbereich Veterinarmedizin der Justus-Liebig-Universitat Giessen: German Federal Republic, p 205 (cf: Vetcd1973-1988).

[47] Sukhija, S.S. (1984) Studies on Certain Morphological and Biochemical Changes in Buffalo Spermatozoa during 
Freeze Preservation. Ph.D. Thesis, Haryana Agricultural University, Hissar.

[48] Alvarez, J.G. and Storey, B.T. (1992) Evidence for Increased Lipid Peroxidative Damage and Lose of Superoxide Dismutase Activity as a Mode of Sub Lethal Crydamage to Human Sperm during Cryopreservation. Journal of Andrology, 13, 232-241.

[49] Bell, M., Wang, X., Hellstrom, W.J. and Sikka, J.K. (1993) Effect of Cryoprotective Additives and Crypreservation Protocol on Lipid Membrane Proxidation and Recovery of Motile Human Sperm. Journal of Andrology, 14, 472-478.

[50] Jackson, M.J. and Edwards, R.H.T. (1988) Free Radicals, Muscle Damage and Muscular Dystrophy. In: Quintanilha, A., Ed., Reactive Oxygen Species in Chemistry, Biology and Medicine. Series A: Life Sciences, Vol. 146. Plenum Press, New York, 197-210. http://dx.doi.org/10.1007/978-1-4757-0417-4_14 


\section{Appendix}

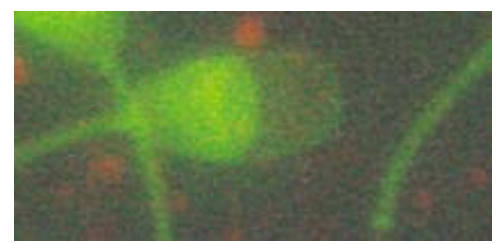

Figure 1. Denuded/lost acrosome.

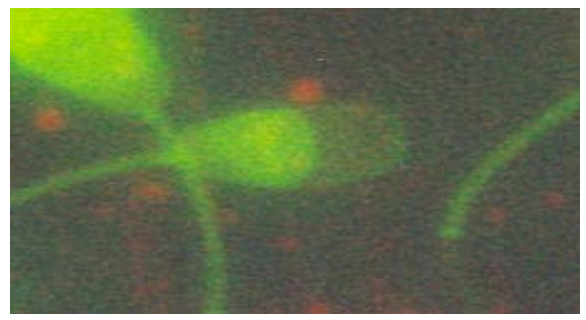

Figure 2. Elongated head with lost acrosome.

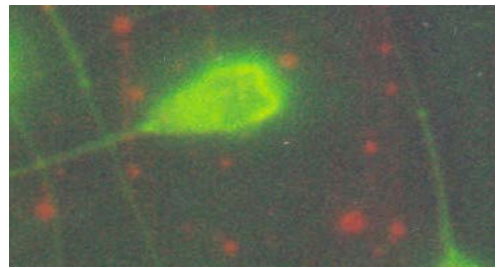

Figure 3. Ruffled crosome.
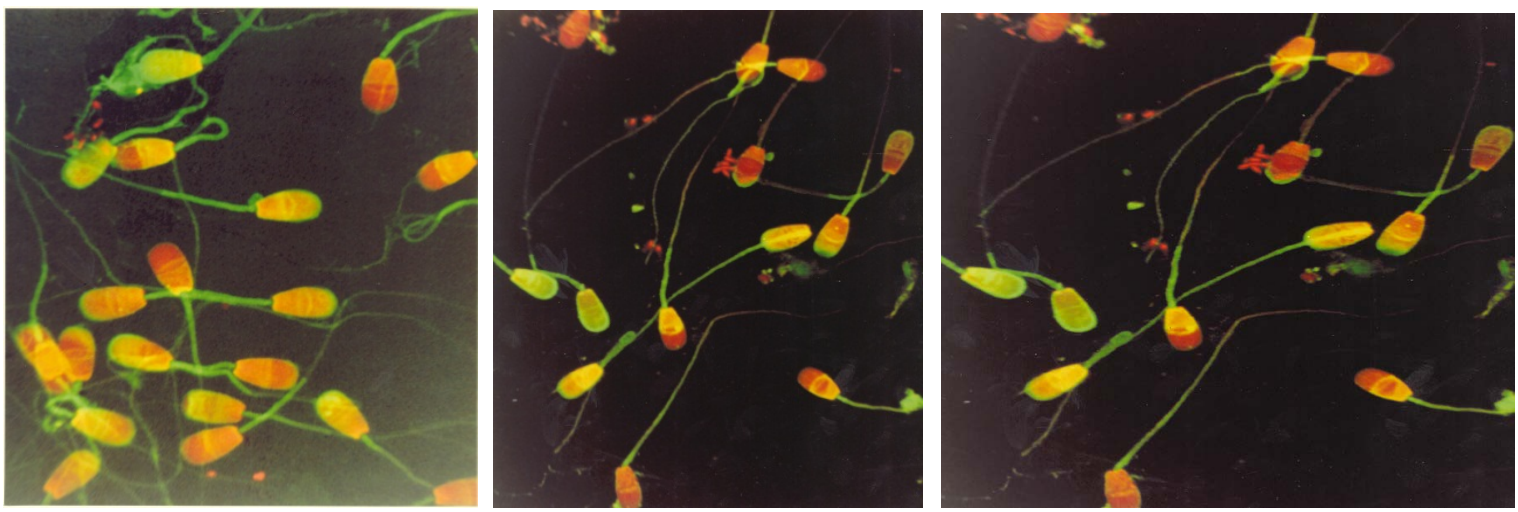

Figure 4. Sperm cells showing different stages of acrosome reacted live, acrosome reacted dead, intact acrosome live and intact acrosome dead sperm cell. 